\title{
The Preparation and Performances of Self-Dispersed Nanomicron Emulsified Wax Solid Lubricant Ewax for Drilling Fluids
}

\author{
Feng-shan Zhou, ${ }^{1}$ Ting-ting Wang, ${ }^{1}$ Zheng-qiang Xiong, ${ }^{2}$ Wen-yue Guo, \\ Xi Xiang, ${ }^{1}$ Huan-na Wang, ${ }^{1}$ Xia-lei Zhu, ${ }^{1}$ Fang Liu, ${ }^{1}$ and Bao-lin Cui ${ }^{1}$ \\ ${ }^{1}$ School of Materials Science and Technology, China University of Geosciences, Beijing 100083, China \\ ${ }^{2}$ Beijing Institute of Exploration Engineering, Beijing 100083, China \\ Correspondence should be addressed to Feng-shan Zhou; zhoufs@cugb.edu.cn
}

Received 5 October 2013; Accepted 14 December 2013; Published 17 April 2014

Academic Editor: Yizhuang Xu

Copyright (c) 2014 Feng-shan Zhou et al. This is an open access article distributed under the Creative Commons Attribution License, which permits unrestricted use, distribution, and reproduction in any medium, provided the original work is properly cited.

An oil-in-water nanomicron wax emulsion with oil phase content $45 \mathrm{wt} \%$ was prepared by using the emulsifying method of surfactant-in-oil. The optimum prepared condition is $85^{\circ} \mathrm{C}, 20 \mathrm{~min}$, and $5 \mathrm{wt} \%$ complex emulsifiers. Then the abovementioned nanomicron emulsifying wax was immersed into a special water-soluble polymer in a certain percentage by the semidry technology. At last, a solidified self-dispersed nanomicron emulsified wax named as Ewax, a kind of solid lubricant for water based drilling fluid, was obtained after dried in the special soluble polymer containing emulsifying wax in low temperature. It is shown that the adhesion coefficient reduced rate $\left(\Delta K_{f}\right)$ is $73.5 \%$ and the extreme pressure (E-P) friction coefficient reduced rate $(\Delta f)$ is $77.6 \%$ when the produced Ewax sample was added to fresh water based drilling fluid at dosage $1.0 \mathrm{wt} \%$. In comparison with other normal similar liquid products, Ewax not only has better performances of lubrication, filtration loss control property, heat resistance, and tolerance to salt and is environmentally friendly, but also can solve the problems of freezing in the winter and poor storage stability of liquid wax emulsion in oilfield applications.

\section{Introduction}

Drilling fluid lubricants can be generally divided into liquid lubricants and solid lubricants according to their existential status, the former typically containing liquid mineral oil, vegetable oil, and surfactant while the latter including solid graphite, plastic ball, glass bead, and so on. However, the liquid lubricants such as mineral oil and vegetable oil always freeze at low temperature, and meanwhile the amount of these toxic lubricants like mineral oil, asphalt, and graphite for industrial utilization is reducing gradually year by year due to environmental protection requirement [1]. Hence, it is significant and urgent to develop a kind of solid lubricant with less toxicity and good feasibility at low temperature for drilling mud.

It is acknowledged that wax is a kind of oil organics with strong cohesive force and neither water soluble nor saponification. Thus, wax emulsion applied in multiple phase disperse systems shows good stability and dispersibility even without heating to melted or organic solvent for dissolved. Wax emulsion expressed good lubricity in drilling fluid by forming a well-distributed film on the drilling string and borehole wall. In addition, wax emulsion also has other superiorities such as low fluorescence, nontoxicity, and noncorrosiveness. All of the above-distinguished properties endow wax emulsion as an important special wax product.

The nanomicron wax emulsion with stable particles was introduced into drilling fluid by Wang et al. [2-4] from Shandong University; since then, wax emulsion has become focus in many applied researches. So far, it has been well recognized that nanomicron wax emulsion possesses good lubricity performance and inhibitive ability. In spite of these distinguished properties, it shows many defects in storage stability, antifreeze property, filtration property, and cost performance which prevent wax emulsion from promoting conveniently. 
In order to solve the above problems, this work investigated the preparation technology of self-dispersed nanomicron emulsified wax solid lubricant based on wax and its derived by-products. Meanwhile, its drilling performances such as lubricity performance, rheological behavior, filtration loss control in high temperature and high pressure (HTHP), tolerance to salt, and inhibitive ability for shale formations were also evaluated in depth in this work.

\section{Experimental Details}

2.1. Materials and Instruments. The all industrial grade samples such as wax, ceratum, white oil, and sodium hydroxide are purchased from Beijing Chemical Reagent Co., Ltd., China. The multicomponent emulsifier TE, inorganicorganic compound stabilizer TS, and a special water soluble polymer cellulose graft starch (PPS) are self-made.

Model NF-1 adhesion coefficient tester for drilling fluid, Model GGS42-2 high-temperature high-pressure filter press apparatus, and Model ZNN-D6S six-speed rotational viscometer are made in Haitongda Special Instruments Co., Ltd, China. The digital extreme pressure (EP) lubricity tester for drilling fluids was made in OFITE, USA. Model F4600 fluorescence spectrophotometer was made in Hitachi, Japan. Mastersizer 2000 laser particle analyzer was made by Malvern Instruments Ltd, England. JSM-6460LV high resolution scanning electron microscope was made in JEOL, Japan.

\subsection{Performance Evaluation Methods}

2.2.1. Lubricity Evaluation. The adhesion coefficient reduced rate $\left(\Delta K_{f}\right)$ and the extreme pressure (E-P) friction coefficient reduced rate $(\Delta f)$ were applied to evaluate the lubricity performances and specific evaluation can refer to the technical standard from China National Petroleum Corporation (CNPC) of liquid lubricants for water based drilling fluid (Q/SY 1088-2007).

2.2.2. Rheological Behavior Evaluation. Apparent viscosity $(\mathrm{AV})$, plastic viscosity (PV), yield point (YP), and API (American Petroleum Institute) filter loss $\left(\mathrm{FL}_{\mathrm{API}}\right)$ were applied to evaluate the rheological behavior and specific evaluation method can refer to China national standards "petroleum and natural gas industries-field testing of drilling fluids-part 1: water-based fluids (GB-T 16783.1-2006)".

2.2.3. Filtration Property Evaluation. The evaluation method of filtration property can refer to the technical profession standard of filtrate reducer tolerant to salt and high temperature for drilling fluid (Q/SH 0047-2007).

2.2.4. Fluorescence Performance Evaluation. According to the measuring method of the fluorescence emitted by the drilling fluid additive reported by Patel et al. [5], three-dimensional fluorescence spectrum was used to quantitatively measure the maximum fluorescence intensity $F_{\max }$, the optimum excitation wavelength $\mathrm{EX}$, and the corresponding emission wavelength EM. The detailed measuring method was described as follows: the test samples and hexane were mixed at mass ratio 1:400 first followed by the fluorescence characteristic measurement performed on fluorescence spectrophotometer. The main test parameters were listed as follows: the slit width of the excitation wavelength is $2.5 \mathrm{~nm}$; the slit width of the emission wavelength is $2.5 \mathrm{~nm}$; PMT voltage is $700 \mathrm{~V}$; scanning speed is $1200 \mathrm{~nm} / \mathrm{min}$.

2.2.5. Microscope Structure. The measuring method and scattering condition were set on laser particle analyzer Mastersizer 2000 according to the ISO 13320 standard operation procedure and Mie Theory.

\subsection{Preparation}

2.3.1. Preparation of Wax Emulsion. Wax and its derived byproducts were selected as the raw materials and they were heated together with white oil to get melted in a three-round flask. Then $\mathrm{NaOH}$ solution was added into the above mixture for preemulsification, as plenty of experiments and researches [6-8] indicated that the emulsification effect of compound emulsifier compounded by two or more surfactants took distinguished advantages over that of the single emulsifier. Span-80 and Tween-80 were certainly selected as the principal emulsifier while surfactant $A$ and $B$ were taken as the coemulsifiers in this work to obtain compound emulsifier TE which was added into the system after the preemulsification reaction. The emulsion stabilizer TS and other modifiers were selectively added into the system repeatedly to adjust the water phase. With the emulsifying method of surfactant-inoil, the stable nanomicron wax emulsion was prepared under the optimized condition: emulsifying time was 20 minutes and emulsifying temperature was $85^{\circ} \mathrm{C}$ which slowly cooled to room temperature in the process of stirring.

2.3.2. Preparation of the Solid Wax Lubricant. The nanomicron wax emulsion made from Section 2.3.1 and a kind of special water soluble polymer material PPS were mixed together to react sufficiently at certain temperature for a period of time in kneader via the semidry technology $[9,10]$. The self-dispersed nanomicron emulsified wax solid lubricant Ewax was finally obtained after the sample was dried at low temperature and broken to pieces. The complete preparation technological process was illustrated in Figure 1.

\section{Impact of Ewax on the Performance of Drilling Fluid}

3.1. Lubricity Performance. Figure 2 shows the effect of Ewax additive dosage on the adhesion coefficient reduced rate $\left(\Delta K_{f}\right)$ and the extreme pressure (E-P) friction coefficient reduced rate $(\Delta f)$ of sodium bentonite based mud for experimental utilization with $5.2 \mathrm{wt} \%$. As indicated in Figure 2, when the additive dosage of Ewax was $0.5 \mathrm{wt} \%, 1.0 \mathrm{wt} \%$, $1.5 \mathrm{wt} \%$, and $2.0 \mathrm{wt} \%$; the lubricity performance of the based 


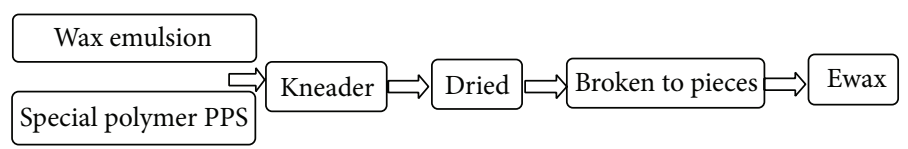

FIGURE 1: The preparing process for solid lubricant Ewax.

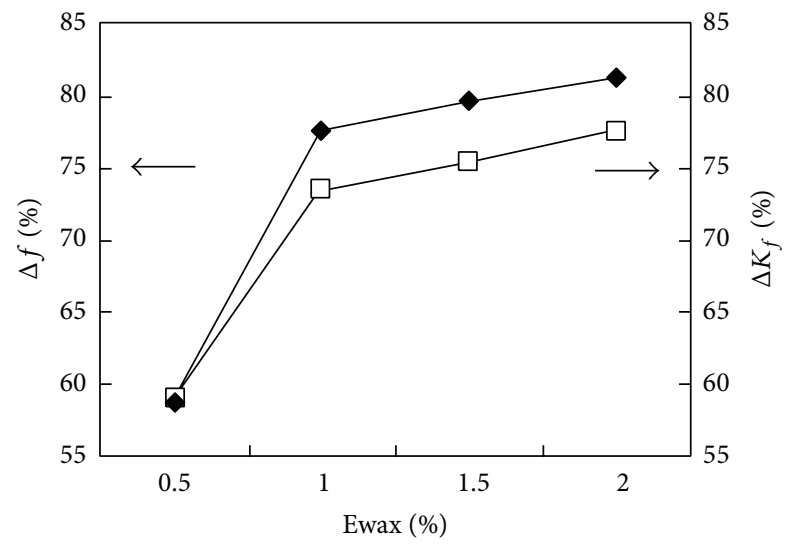

FIGURE 2: Effect of Ewax additive dosage on lubrication.

mud was generally enhanced continuously as suggested by the positive slope of the curve, which was much steep between the first two points but rather steady for the last three points. Nevertheless, if the impact of the produced sample additive dosage on drilling fluid system and the cost of treatment agents were both taken into account for the final evaluation, it was reasonable to conclude that the Ewax additive dosage at $1.0 \mathrm{wt} \%$ was appropriate. Therefore, $1.0 \mathrm{wt} \%$ was determined as the unified dosage for the evaluation of drilling fluid performances before and after adding Ewax.

The drilling additive could be seriously affected by temperature and salinity in the process of oilfield drilling. The lubricity performance of both the fresh water based mud and $4.0 \mathrm{wt} \%$ brine base mud was investigated in depth with the Ewax additive dosage at $1.0 \mathrm{wt} \%$. Besides, the comparable evaluation was also made between the lubricity performance of the system at room temperature (RT) and that of the same system aged at high temperature $\left(120^{\circ} \mathrm{C} \times 16 \mathrm{~h}\right)$ just as shown in Table 1.

As it can be clearly seen in Table 1 that $\Delta K_{f}$ and $\Delta f$ of fresh water based mud with $1.0 \mathrm{wt} \%$ Ewax aged for $16 \mathrm{~h}$ at $120^{\circ} \mathrm{C}$ slightly decreased compared to that of the same system at room temperature. However, the situation was rather different in the $4.0 \mathrm{wt} \%$ brine based mud in which $\Delta K_{f}$ of the system aged for $16 \mathrm{~h}$ at $120^{\circ} \mathrm{C}$ ascended while its $\Delta f$ almost kept the same value. This suggested that Ewax possessed good lubricity performance in both fresh water and $4.0 \mathrm{wt} \%$ brine based mud. Besides, it also exhibited superior resistance ability to high temperature and salt.

Table 2 showed the comparison results of the performances of Ewax and other lubricants. Apparently, Ewax possessed better overall lubricity performance over other commercial lubricant products in China including DZ (from Dezhou, Shandong), DY (from Dongyin, Shandong),
TABLE 1: Lubricity evaluation of Ewax in different based mud and at different temperature.

\begin{tabular}{lcccc}
\hline $\begin{array}{l}\text { Ewax additive } \\
\text { dosage/wt\% }\end{array}$ & Based mud & Condition & $\Delta K_{f} / \%$ & $\Delta f / \%$ \\
\hline 1.0 & Fresh water $^{\mathrm{a}}$ & R.T. & 73.5 & 77.6 \\
& \multirow{2}{*}{$1.00^{\circ} \mathrm{C} \times 16 \mathrm{~h}$} & 63.8 & 68.0 \\
& & R.T. & 76.5 & 64.1 \\
& & $120^{\circ} \mathrm{C} \times 16 \mathrm{~h}$ & 78.5 & 63.1 \\
\hline
\end{tabular}

Remarks: ${ }^{a}$ fresh water based mud is $5.2 \%$ bentonite based mud; ${ }^{b}$ brine based mud is $5.2 \%$ bentonite based mud adding $4.0 \% \mathrm{NaCl}$.

Slube (from Bingzhou, Shandong), and GD-2 (from Renqiu, Hebei).

3.2. Rheological Behavior. The rheological behavior of drilling fluid could reflect its flow and deformation properties which were measured by shear stress and shear rate [11]. It is well recognized that the rheological behavior of drilling fluid is directly related to many factors such as its washdown capability to shaft bottom, solids carrying and suspending capability, the delivery ability of water power, and wall stabilization. The changing result of rheological behavior of drilling fluid based mud before and after the addition of Ewax was shown in Table 3.

As indicated in Table 3, AV, PV, and $\mathrm{Gel}_{10^{\prime \prime} / 10^{\prime}}$ of the system showed little change before and after the addition of Ewax, suggesting that Ewax had almost no influences on the rheological behavior of drilling fluid. Meanwhile, YP of the system increased slightly and 30 min $\mathrm{FL}_{\mathrm{API}}$ decreased a little after the addition of Ewax indicating that Ewax showed certain filtration loss control effect which was beneficial to ensure the wellbore stability.

3.3. HTHP Filtration Loss. Filtrate loss reducer is a kind of important drilling fluid additive to ensure the stable performance of drilling fluid. It was reported that the stable wellbore as well as regular and consistent borehole gauge could be achieved via reducing the invasion of drilling fluid into stratum and preventing the hydrating and swelling of

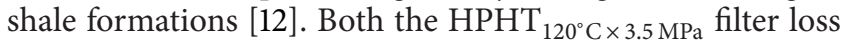
performance in fresh water based mud and $4.0 \mathrm{wt} \%$ brine based mud were tested and compared to those of other two products DZ and DY as recorded in Table 4. The brine based mud was obtained based on the fresh water based mud by adding $4.0 \mathrm{wt} \% \mathrm{NaCl}$ into it under vigorous stirring for $20 \mathrm{~min}$ followed by the addition of $1.0 \mathrm{wt} \%$ Ewax under continuously stirring for another $5 \mathrm{~min}$. It was clear in Table 4 that Ewax exhibited fluid loss property in both fresh water and brine based mud, with the latter being more apparent. 
TABLE 2: Comparison of different lubricants.

\begin{tabular}{|c|c|c|c|c|c|}
\hline Sample & Principal component & Particle size & Product modality & $\Delta K_{f} / \%$ & $\Delta f / \%$ \\
\hline Ewax & wax (ceratum) & nanomicron & solid & 73.5 & 77.6 \\
\hline $\mathrm{DZ}$ & wax & nanoscope & emulsion & 65.3 & 72.5 \\
\hline DY & wax & nanoscope & emulsion & 71.5 & 73.3 \\
\hline Slube & Inflating crystalline graphite & nanomicron & solid & 57.0 & 64.0 \\
\hline GD-2 & Crystalline graphite & nanomicron & solid & 26.3 & 65.0 \\
\hline
\end{tabular}

TABLE 3: Impact of Ewax on drilling fluid rheology.

\begin{tabular}{lcccccc}
\hline Mud type & Ewax additive dosage/wt\% & $\mathrm{AV} / \mathrm{mPa} \cdot \mathrm{s}$ & $\mathrm{PV} / \mathrm{mPa} \cdot \mathrm{s}$ & $\mathrm{YP} / \mathrm{Pa}$ & $\mathrm{Gel}_{10^{\prime \prime}} / 10^{\prime} /(\mathrm{Pa} / \mathrm{Pa})$ & $\mathrm{FL}_{\mathrm{API}} /(\mathrm{mL} / 30 \mathrm{~min})$ \\
\hline \multirow{2}{*}{ Fresh water based mud } & 0 & 13.5 & 7.0 & 6.5 & $6.5 / 12.0$ & 14.0 \\
& 1.0 & 15.5 & 8.0 & 7.5 & $6.0 / 11.5$ & 12.2 \\
\hline \multirow{2}{*}{ Drilling fluid $^{\mathrm{bc}}$} & 0 & 13.5 & 11.0 & 2.5 & $1.0 / 1.0$ & 10.0 \\
& 1.0 & 13.5 & 10.0 & 3.5 & $1.0 / 1.0$ & 9.6 \\
\hline
\end{tabular}

Remarks: ${ }^{a}$ fresh water based mud is $6.0 \mathrm{wt} \%$ sodium-bentonite based mud.

${ }^{\mathrm{b}}$ Drilling fluid is $4.0 \mathrm{wt} \%$ sodium-bentonite based mud + 0.2 wt $\%$ HV-CMC + $0.3 \mathrm{wt} \% \mathrm{NPAN}+0.2 \mathrm{wt} \% \mathrm{SiM}+0.1 \mathrm{wt} \%$ KPAM.

${ }^{c} \mathrm{HV}-\mathrm{CMC}$ is technical-grade high-viscosity carboxymethylcellulose as viscositier; NPAN is hydrolysed ammonium polyacrylonitrile as filter loss control agent; SiM is silicone grafted starch film former as inhibitor; KPAM is potassium copolymer of acrylamide and acrylic acid as flocculant.

TABLE 4: Comparison of HTHP filtration loss control ability.

\begin{tabular}{|c|c|c|c|c|c|c|}
\hline \multirow[t]{2}{*}{ Sample } & \multicolumn{2}{|c|}{ Fresh water based mud ${ }^{\mathrm{a}}$} & \multicolumn{2}{|c|}{ Brine based mud ${ }^{\mathrm{b}}$} & \multicolumn{2}{|c|}{$\begin{array}{c}\text { Brine based mud } \\
\text { Aged at high temperature }\end{array}$} \\
\hline & $A^{\mathrm{d}}$ & $B^{\mathrm{e}}$ & $A$ & $B$ & A & $B$ \\
\hline Based mud & 29.0 & - & 78.0 & - & 98.0 & - \\
\hline Ewax & 19.0 & 34.5 & 38.0 & 51.3 & 49.0 & 50.0 \\
\hline $\mathrm{DZ}$ & 25.0 & 13.8 & 75.0 & 3.9 & - & - \\
\hline DY & 24.5 & 15.5 & 74.5 & 4.5 & - & - \\
\hline
\end{tabular}

Remarks: ${ }^{\text {a }}$ fresh water based mud is $6.0 \%$ bentonite based mud.

${ }^{\mathrm{b}}$ Brine based mud is $6.0 \%$ bentonite based mud added $4.0 \% \mathrm{NaCl}$.

${ }^{\mathrm{c}}$ Brine based mud aged at high temperature is $6.0 \%$ bentonite based mud added $4.0 \% \mathrm{NaCl}$ aged at $120^{\circ} \mathrm{C}$ for $16 \mathrm{~h}$.

${ }^{\mathrm{d}} A$ is filter loss in $\mathrm{mL} / 30 \mathrm{~min}$.

${ }^{\mathrm{e}} B$ is reducing rate of water loss in percent.

The reducing rate of water loss of brine based mud even approached 51.3\%, 10 times higher than the same kind of products.

In order to investigate the filtration control performance of Ewax at high temperature and salinity, $\mathrm{HPHT}_{120^{\circ} \mathrm{C} \times 3.5 \mathrm{MPa}}$ filter loss performance testing was taken on brine base mud containing $6.0 \mathrm{wt} \%$ bentonite base mud and $4.0 \mathrm{wt} \% \mathrm{NaCl}$ and its mixture with Ewax together aged at $120^{\circ} \mathrm{C}$ for $16 \mathrm{~h}$ as shown in Table 4. The reducing rate of filter loss as high as $50.0 \%$ indicated that Ewax shows superior resistance ability to high temperature and salt in filtration control ability, which took distinguished advantage over other similar products.

3.4. Inhibitive Ability. The inhibitive ability of drilling additives is mainly shown in two aspects: preventing the hydrating and swelling of shale formations and its scattering. In this work, the inhibitive ability of Ewax was simulated by measuring the reducing rate of yield of clay. First, Ewax and Na-bentonite were added together into distilled water and the rheological parameters were measured after a 12hour hydration process. Meanwhile, comparable result with bentonite based mud without any Ewax was made as recorded in Table 5. Clearly, AV and PV of the based mud containing Ewax both decreased together with the decrease of the yield of clay suggesting that Ewax could inhibit clay from hydrating and swelling.

3.5. Microscope Structure. Figure 3 is SEM images of the produced wax emulsion, and Figure 4 is the laser particle size distribution of wax emulsion (a) and Ewax (b), respectively. Apparently, the size of wax emulsion particles was generally distributed between $200 \mathrm{~nm}$ and $10 \mu \mathrm{m}$ as shown in Figure 3 while that of Ewax was generally distributed between $0.3 \mu \mathrm{m}$ and $120 \mu \mathrm{m}$ as shown in Figure 3. These two particle distribution spectra further confirmed that the nanomicron emulsified wax solid lubricant was obtained which could disperse well in base mud and drilling fluid and plug the pore like what nanomicron wax did to protect the stability of the formations.

Figure 5 showed the scanning electron photographs of the particles morphology of special water-soluble polymer material (a) and Ewax (b). Obviously, the emulsified wax 
TABle 5: Inhibitive ability of Ewax.

\begin{tabular}{|c|c|c|c|c|}
\hline Based mud & $\mathrm{AV} /(\mathrm{mPa} \cdot \mathrm{s})$ & $\Delta \mathrm{AV} / \%$ & $\mathrm{PV} /(\mathrm{mPa} \cdot \mathrm{s})$ & $\Delta \mathrm{PV} / \%$ \\
\hline $6.0 \mathrm{wt} \%$ bentonite $\rightarrow \mathrm{a} 12 \mathrm{~h}$ hydration process & 13.5 & - & 7.0 & - \\
\hline $1.0 \mathrm{wt} \%$ Ewax $+6.0 \mathrm{wt} \%$ bentonite $\rightarrow \mathrm{a} 12 \mathrm{~h}$ hydration process & 11.5 & 14.8 & 6.0 & 14.3 \\
\hline
\end{tabular}

TABLE 6: Fluorescence performance of Ewax.

\begin{tabular}{lccc}
\hline Sample & $F_{\max }$ & $\mathrm{EX} / \mathrm{nm}$ & $\mathrm{EM} / \mathrm{nm}$ \\
\hline Ewax & 176.4 & 256.0 & 436.2 \\
\hline
\end{tabular}

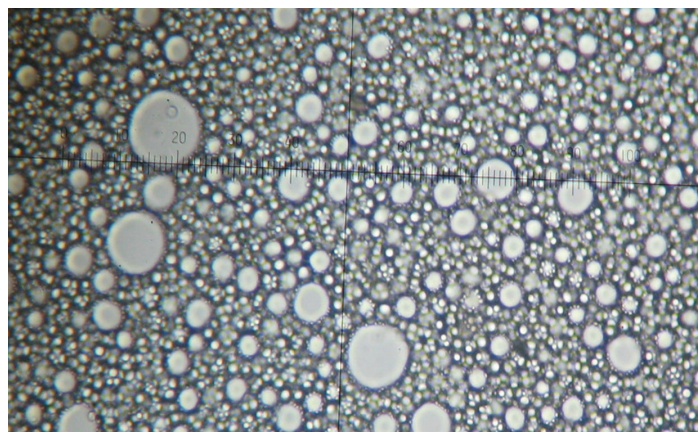

FIGURE 3: SEM images of the produced wax emulsion.

covered the surface of the special polymer material in the form of wax spheres as shown in Figure 5(b) and made the polymer's surface much smoother, which was critical for the appearance of good lubricity performance. Besides, the particle size of Ewax was also shown to be about $20 \mu \mathrm{m}$, consistent with the result in Figure 3.

3.6. Fluorescence Performance. Three-dimensional fluorescence spectrum was employed to quantitatively measure the maximum fluorescence intensity $F_{\max }$, the optimum excitation wavelength EX, and the corresponding emission wavelength EM. It was reported in the patent by Patel et al. [5] that the additive would emit strong fluorescence when its $F_{\max }$ was beyond 800 . As shown in Figure 6 and Table 6 , the maximum fluorescence intensity $F_{\max }$ of Ewax was only 176.4, suggesting that its fluorescence level was relatively low. Meanwhile, the characteristic peak of Ewax was at 256.0/436.2 and did not overlap with that of the crude oil and natural gas shown in Table 7 [13], indicating that Ewax would not influence the geological logging process to explore oil and gas.

3.7. Antiadhesion Performance. Adhesion phenomenon might appear in the long-time storage and transportation process of solid wax powder. The following method was applied to evaluate the antiadhesion performance in this work: firstly, certain amount of sample (more than $200 \mathrm{~g}$ ) was put into a sealed bag which should consequently be squeezed heavily to let the air out. After the sample was pressured to be flattened, it should be transferred into a constant temperature oven followed by a 24-hour pressure process at $50 \mathrm{kPa}$ at $50^{\circ} \mathrm{C}-60^{\circ} \mathrm{C}$ on the surface of the sample. Finally,

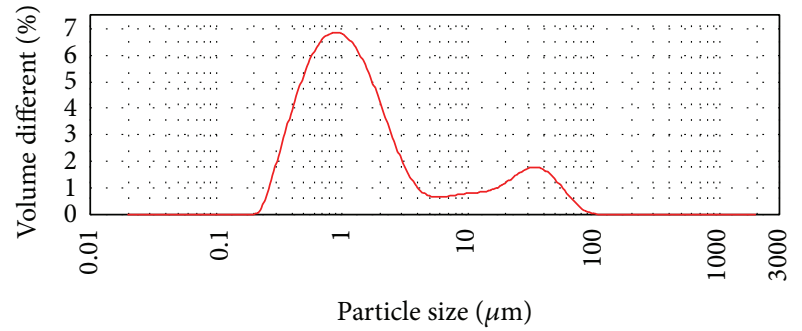

(a)

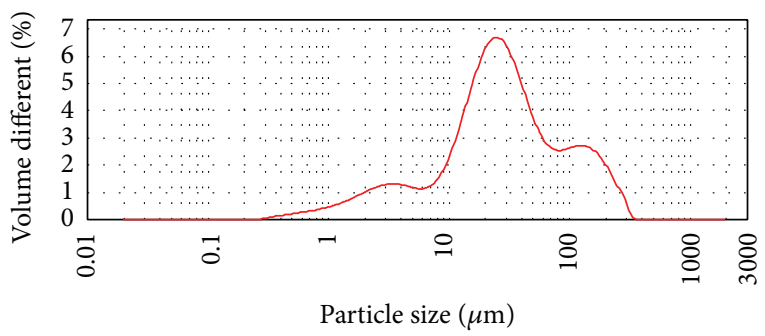

(b)

FIGURE 4: Laser particle size distribution of wax emulsion (a) and Ewax (b).

the sample should be taken out to examine its adhesion state and dispersion property. The results already indicated that pressure did not have any effect on the lubricity performance and dispersion property of Ewax, which showed good antiadhesion performance.

3.8. Environmentally Friendly Behavior. As the absorption carrier in this experiment was a kind of special watersoluble polymer PPS with good biodegradability and the main lubricity component was wax, all these materials would not do any harm to the environment. Besides, wax spheres with low fluorescence intensity could plug the pore and flow back easily, which would not disrupt the geological logging process. This great advantage made it possess light application prospect in mainland drilling especially for marine drilling. From the above discussion, it was clear to conclude that Ewax was a kind of environmentally friendly drilling fluid solid lubricant product.

\section{Conclusions}

(1) The optimized technology with wax or ceratum as basic raw materials was finally established in which emulsifying temperature is $85^{\circ} \mathrm{C}$, emulsifying time is $20 \mathrm{~min}$, complex emulsifiers is $5 \mathrm{wt} \%$, and oil phase content is $45 \mathrm{wt} \%$. The uniform and stable 
TABLE 7: Three-dimensional fluorescence spectra features of different crude oil and natural gas.

\begin{tabular}{lccc}
\hline Characteristic peak EX/EM & $268 / 322$ & $284 / 336$ & $256 / 360$ \\
\hline Oil and gas properties & $\begin{array}{c}\text { Gas and } \\
\text { condensate gas }\end{array}$ & $\begin{array}{c}\text { Condensate oil and } \\
\text { light oil }\end{array}$ & $\begin{array}{c}\text { Medium oil and } \\
\text { heavy oil }\end{array}$ \\
\hline
\end{tabular}

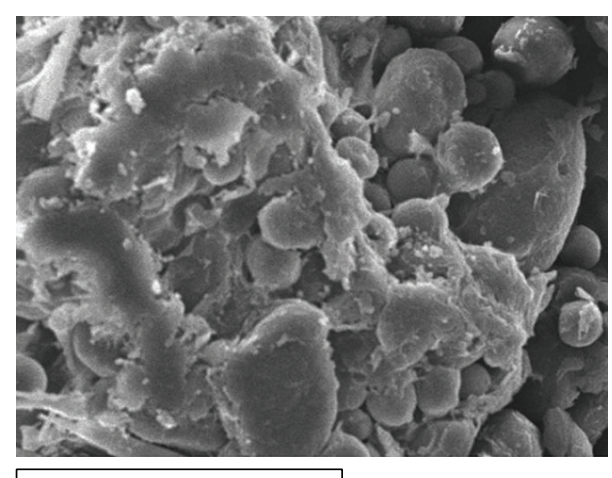

$60 \mu \mathrm{m}$

(a)

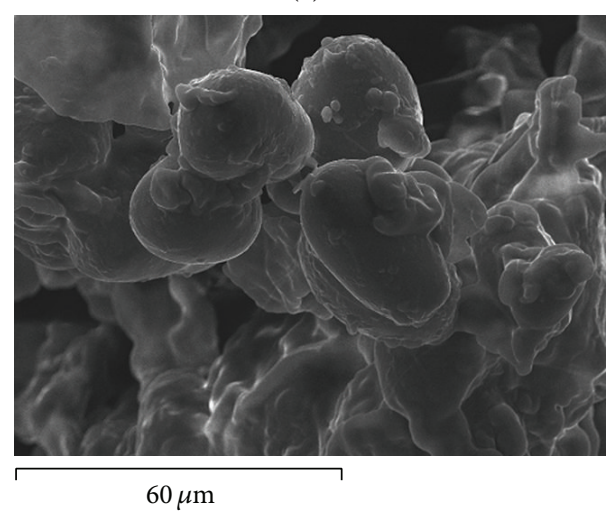

(b)

FIGURE 5: SEM images of special water-soluble polymer (a) and Ewax (b).

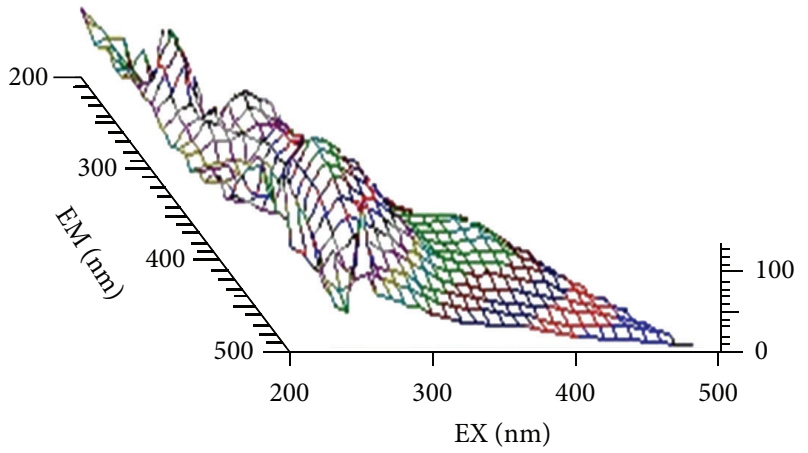

Figure 6: 3D fluorescence spectra of Ewax.

nanomicron wax emulsion was prepared under the optimized process.

(2) A solid self-dispersed nanomicron emulsified wax named as Ewax was prepared by the semidryer technology in which the nanomicron emulsifying wax was immersed into a special water-soluble polymer followed by drying continuously at low temperature.
(3) The adhesion coefficient reduced rate $\left(\Delta K_{f}\right)$ and the extreme pressure (E-P) friction coefficient reduced rate $(\Delta f)$ of the base mud could approach over $70 \%$ when the amount of Ewax in drilling fluid reached $1.0 \mathrm{wt} \%$, indicating its good lubricity performance. Meanwhile, Ewax also exhibited nice HTHP filtration qualities and multiple functions, which made Ewax superior to other similar products.

(4) The preparation of Ewax in this work thoroughly solved the problems of freezing in winter and poor storage stability of traditional emulsified wax liquid lubricants.

\section{Disclaimer}

The authors confirm that the paper is the authors' own work, is original and unpublished, and is not being considered for publication elsewhere, and all authors agree that it should be submitted to Journal of Spectroscopy.

\section{Conflict of Interests}

The authors declare that there is no conflict of interests regarding the publication of this paper.

\section{References}

[1] X.-H. Yang, "Advances in preparation and uses of drilling fluid additives in China in recent 5 years," Oilfield Chemistry, vol. 26, no. 2, pp. 210-217, 2009.

[2] B. F. Wang, Y. D. Zhang, and D. J. Sun, "Preparation and application of wax emulsion," Shandong Chemical Industry, vol. 33, no. 2, pp. 14-17, 2004.

[3] T. Wu and D. J. Sun, "Preparation of wax emulsion and application in dispersion system," Journal of Shandong University, vol. 41, no. 4, pp. 141-144, 2006.

[4] Q. Lan, C.-M. Su, W.-R. Liu, F. Yang, B.-Y. Guo, and D.-J. Sun, "Emulsions and emulsifying technique and their application in drilling and completion fluid technology," Drilling Fluid and Completion Fluid, vol. 23, no. 2, pp. 61-69, 2006.

[5] A. D. Patel, E. Stamatakis, S. Young et al., "High performance water based drilling fluid," US 2008/0009422 A1, 2008-1-10.

[6] Y. X. Liu, C. S. Zhao, and L. Han, "Factors affecting the emulsification of paraffin," Paper Chemicals, vol. 16, no. 4, pp. 30-32, 2004.

[7] Z. M. He, Y. Xue, G. L. Zeng et al., "Application of wax emulsion lubricants in drilling operations in Jiangsu oilfield," Petroleum Drilling Techniques, vol. 38, no. 3, pp. 63-66, 2010.

[8] Y. Tian, J.-C. Zhang, F.-J. Zuo et al., "The laboratory preparation and evaluation of a emulsified wax," Drilling Fluid and Completion Fluid, vol. 25, no. 4, pp. 29-33, 2008. 
[9] G. F. Fanta, H. M. Muijs, K. Eskins, F. C. Felker, and S. M. Erhan, "Starch-containing lubricant systems for oil field aplications," US 6461999 B1, 2002.

[10] X. Wang, P. Yu, and S. Liu, "The synthesis of a solid emulsion lubricant," Drilling Fluid and Completion Fluid, vol. 27, no. 2, pp. 16-88, 2010.

[11] D.-C. Qian, K.-C. Wang, H. Yang et al., "Development and application of cationic surfactant emulsified wax for use in aqueous drilling fluid," Oilfield Chemistry, vol. 26, no. 3, pp. 238241, 2009.

[12] J. Chen, X. Wang, Y. Gao, and J. Zhang, "Application of nanowax emulsion drilling fluid technology in horizontal wells," Drilling Fluid and Completion Fluid, vol. 27, no. 4, pp. 87-89, 2010.

[13] J. Song and B. Tang, "Study on the characteristic and significance of three dimensional fluorescence spectra of petroleum samples," Spectroscopy and Spectral Analysis, vol. 20, no. 1, pp. 115-118, 2000. 

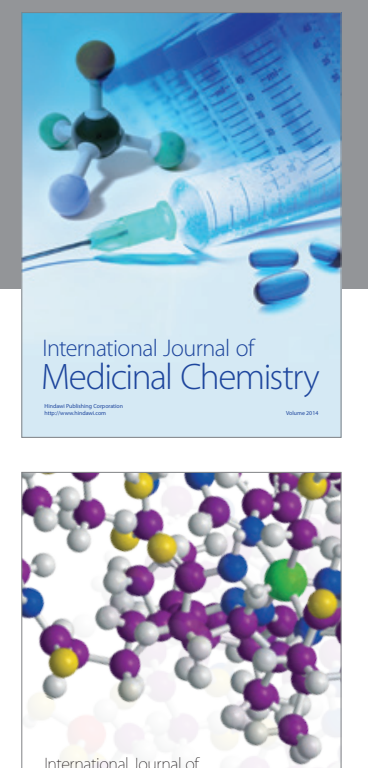

\section{Carbohydrate} Chemistry

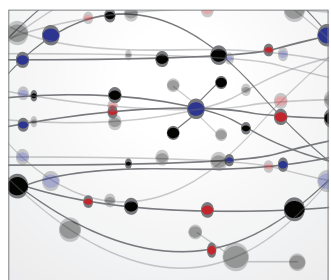

The Scientific World Journal
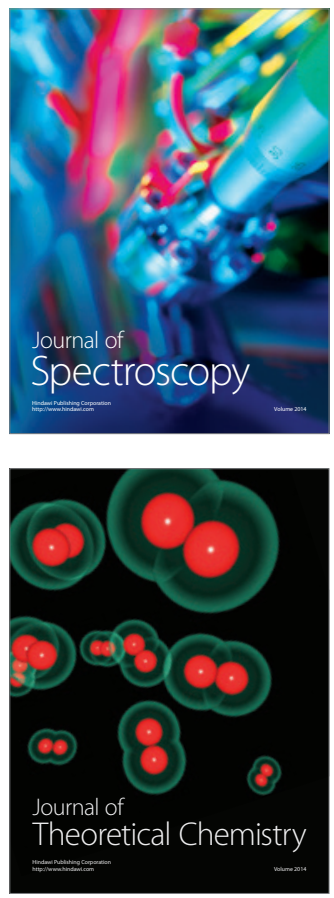
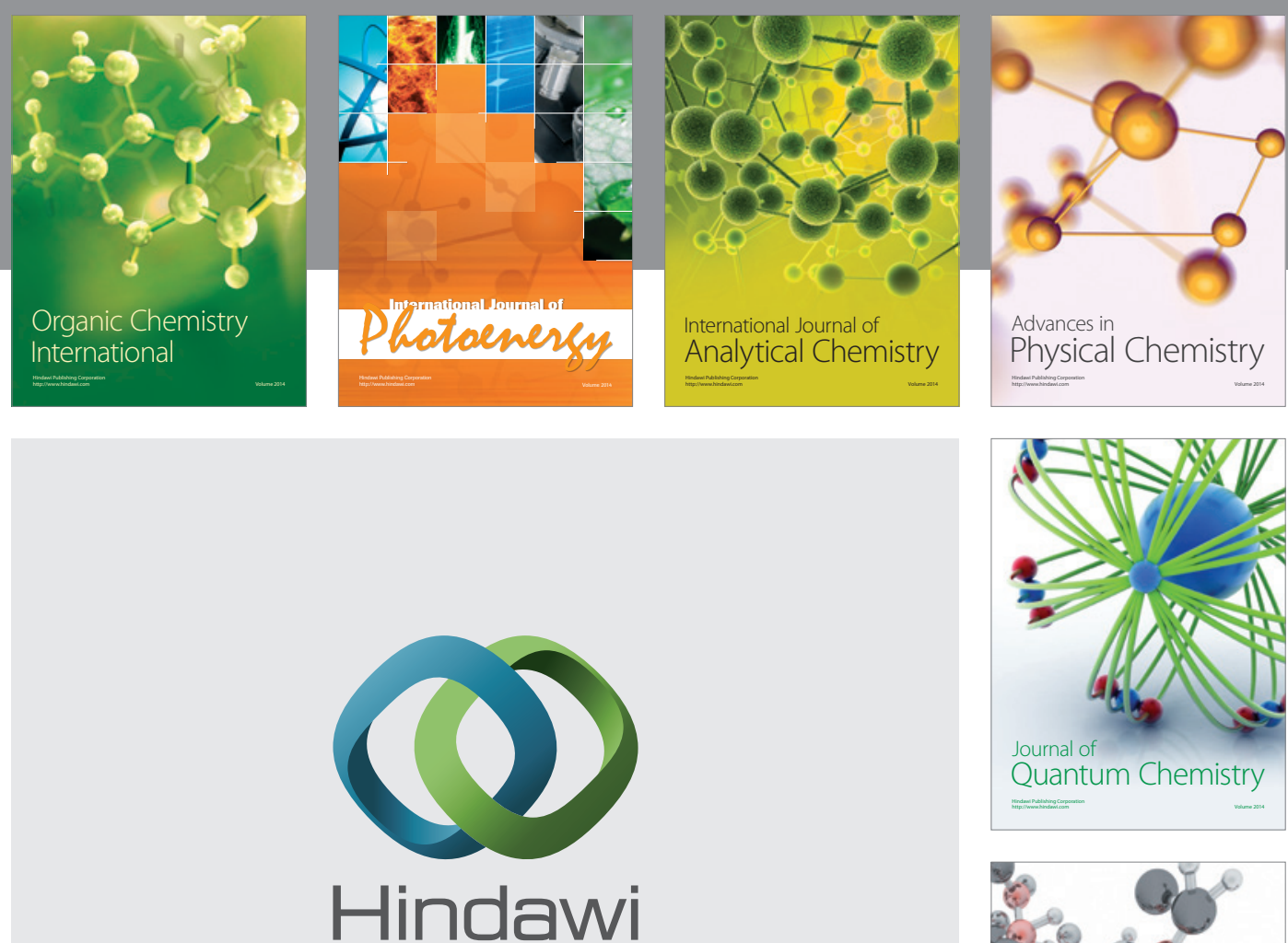

Submit your manuscripts at

http://www.hindawi.com

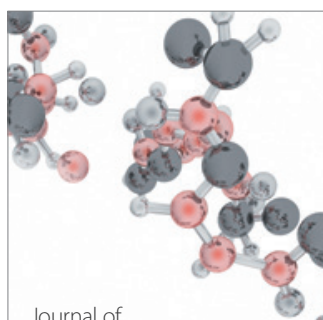

Analytical Methods

in Chemistry

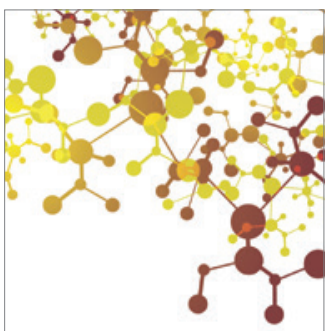

Journal of

Applied Chemistry

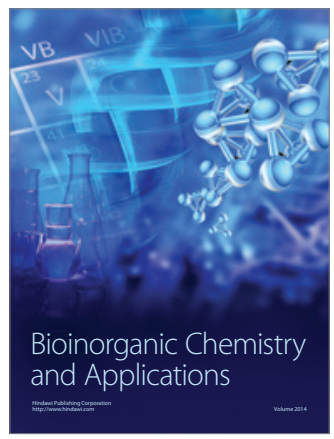

Inorganic Chemistry
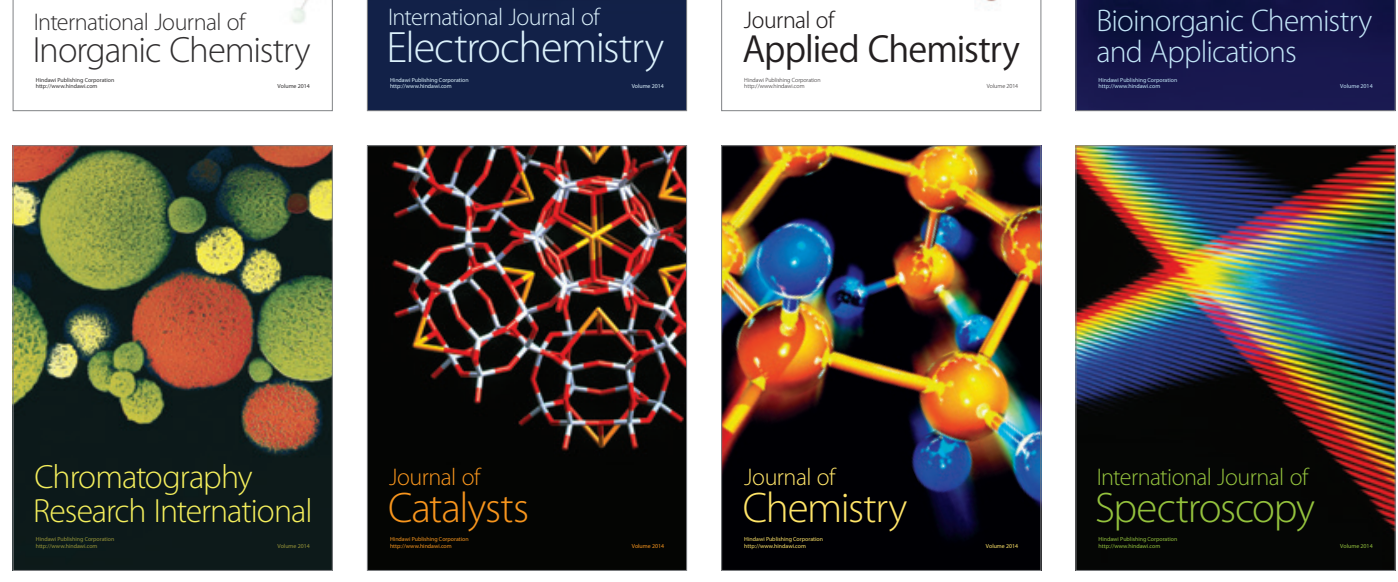